\title{
Long-term results of tenoscopic treatment of lesions in the digital flexor tendon sheath: a retrospective study of fifty horses
}

\section{Langetermijnresultaten van tenoscopische behandeling van letsels in de sesamschede: een retrospectieve studie van vijftig paarden}

\author{
${ }^{1}$ F. Thünker, ${ }^{1} \mathrm{M}$. Oosterlinck, ${ }^{2} \mathrm{~K}$. Vanderperren, ${ }^{1} \mathrm{~A}$. Martens \\ ${ }^{1}$ Department of Surgery and Anesthesiology of Domestic Animals, \\ ${ }^{2}$ Department of Veterinary Medical Imaging and Small Animal Orthopedics, \\ Faculty of Veterinary Medicine, Ghent University, Salisburylaan 133, 9820 Merelbeke
}

Franziska.Thuenker@gmx.de

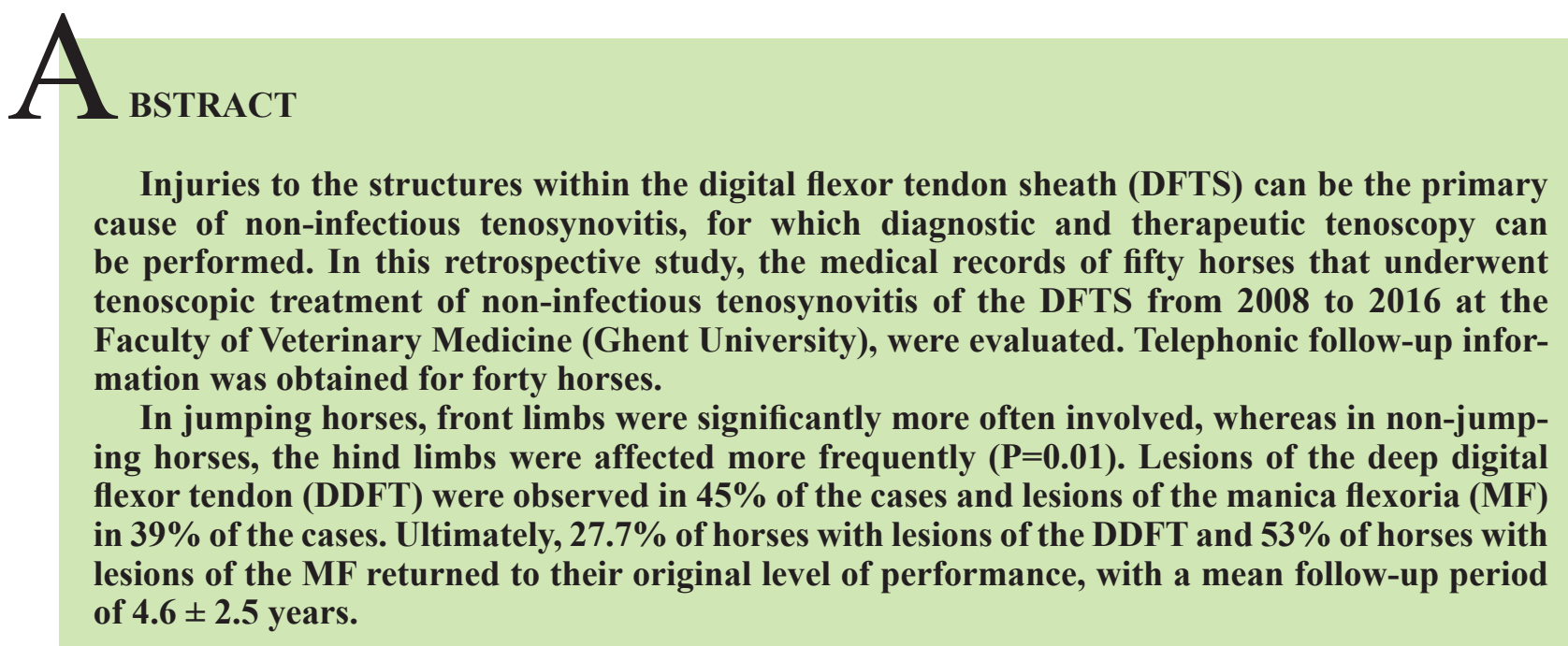

\section{SAMENVATTING}

Letsels ter hoogte van structuren in de sesamschede kunnen de primaire oorzaak zijn van nietinfectieuze tenosynovitis, waarbij tenoscopie zowel diagnostisch als therapeutisch aangewend kan worden. In deze studie werden de gegevens van vijftig paarden uit de databank van de Faculteit Diergeneeskunde (UGent) verzameld, die in de periode van 2008 tot 2016 een tenoscopische behandeling van niet-infectieuze tenosynovitis van de sesamschede ondergingen. Telefonische follow-up informatie kon van veertig paarden worden bekomen.

Bij springpaarden waren de voorbenen significant vaker aangetast dan de achterbenen, terwijl letsels bij paarden die niet voor jumping gebruikt werden, frequenter ter hoogte van de achterbenen werden vastgesteld $(\mathrm{P}=0,01)$. Letsels van de diepe buigpees vertegenwoordigden $45 \%$ van de gevallen terwijl er in 39\% van de gevallen letsels ter hoogte van de manica flexoria waren. Uiteindelijk konden $27,7 \%$ van de paarden met laesies van de diepe buigpees en 53\% paarden met laesies van de manica flexoria terug op hun oorspronkelijk niveau worden ingezet met een gemiddelde follow-upperiode van $4,6 \pm 2,5$ jaar.

\section{INTRODUCTION}

The digital flexor tendon sheath (DFTS) is a synovial structure at the palmar/ plantar aspect of the fetlock region, surrounding the superficial digital flexor tendon (SDFT) and the deep digital flexor tendon (DDFT) (Stanek, 2006; König and Liebich, 2008). The DFTS starts at the distal third of the metacarpus/ metatarsus and ends just proximal of the navicular bursa (König and Liebich, 2008). Three annular ligaments are incorporated into the palmar/ plantar wall of the DFTS (Stanek, 2006; König and Liebich, 2008; Schramme and Smith, 2010). The proximal annular ligament (lig. anulare palmare/plantare) (PAL) surrounds the flexor tendons at the level of the fetlock/ proximal sesamoid bones and may appear as a con- 
strictive band when distension of the DFTS is present. This distension is commonly caused by a lesion within the DFTS. A primary desmitis of the proximal annular ligament is more rarely observed (König and Liebich, 2008; Dyce et al., 2010; Jordana et al., 2013) and may lead to constriction of structures within, and subsequently lead to distension of the DFTS. Distal to the fetlock, the quadrilateral proximal digital annular ligament (lig. anulare digitale proximale) attaches laterally and medially to the proximal phalanx by two bands (Wissdorf et al., 1998; Schramme and Smith, 2010). The middle part of this ligament covers the SDFT and partially adheres to it (Wissdorf et al., 1998; König and Liebich, 2008). The distal digital annular ligament (lig. anulare digitale distale) is located more distally in the pastern and adheres to the terminal portion of the DDFT (König and Liebich, 2008; Schramme and Smith, 2010).

At the level of the fetlock, the SDFT encircles the DDFT with a circular, tendinous structure, known as the manica flexoria (MF) (Schaller et al., 2007; König and Liebich, 2008).

Trauma to structures within the DFTS may result in non-infectious tenosynovitis (Nixon 2002; Stanek, 2006; Schramme and Smith, 2010; Arensburg et al., 2011), which can cause various degrees of lameness and distension of the DFTS, but which can also be subclinical. In acute cases, the distended DFTS may be warm and painful on palpation (Stashak, 2002; Stanek, 2006; Bertone, 2011). In chronic cases, fibrosis and adhesions may hinder adequate palpation of the flexor tendons (Stashak, 2002; Stanek, 2006; Schramme and Smith, 2010; Bertone, 2011).

Intrathecal anesthesia of the DFTS is the most specific anesthesia for localizing injuries to structures within the DFTS (Fortier, 2005; Schramme and Smith, 2010; Fiske-Jackson et al., 2013). However, not all lesions respond similarly to intrathecal anesthesia. Tears of the DDFT typically present a more positive response after intrathecal anesthesia than tears of the $\mathrm{MF}$, and in many cases, only partial improvement is observed after intrathecal anesthesia (Fiske-Jackson et al., 2013). From a diagnostic point of view, it is also important to realize that the effects of intrathecal anesthesia may not be specific. Depending on the injection technique used, leakage of local anesthetic solution may result in inadvertent desensitization of other structures, mainly the foot (Schneider et al.,
2003; Jordana et al., 2012, 2013, 2014). Diffusion to the palmar/ plantar digital nerves causes desensitization at the level of the heel bulbs (Jordana et al., 2014). Jordana et al. (2012) also showed that lower leakage scores were obtained using the injection technique described by Hassel et al. (2000) at the axial aspect of the lateral proximal sesamoid bone. Moreover, this injection technique has been shown to result in the highest number of successful injections compared with three other approaches: at the distal aspect of the DFTS (pastern approach), at the proximal aspect of the DFTS, and at the base of the lateral sesamoid bone (Jordana et al., 2012).

In case of distension, ultrasound examination of the DFTS is very useful to detect underlying pathology and in these cases, all structures related to the DFTS should be evaluated. Ultrasonographic abnormalities may include fluid accumulation within the DFTS, synovial proliferations, adhesions or masses, tears in the flexor tendons or the MF, desmitis of the annular ligaments and tendinitis of the SDFT and DDFT (Edinger et al., 2005; Schramme and Smith, 2010; Bertone, 2011). Distension of the DFTS typically results in an accumulation of synovial fluid between the DDFT and the proximal annular ligament (Arensburg et al., 2011).

False positive and false negative results have been reported on ultrasonographic examination depending on the type of lesion, with exact numbers differing between authors (Edinger et al., 2005; Arensburg et al., 2011; Fiske-Jackson et al., 2013). Lesions of the MF are more often underestimated than lesions of the DDFT, but there are more false positive results for lesions of the DDFT (Fortier, 2005; Arensburg et al., 2011; Fiske-Jackson et al., 2013; Cauvin and Smith, 2014). In different studies, data have been reported on diagnostic sensitivity and specificity of ultrasound examination for lesions of the MF and the DDFT, which are summarized in Table 1.

Contrast radiography has been reported to have an excellent sensitivity for lesions of the MF (96\%), whereas the sensitivity for lesions involving the DDFT is lower (57\%) (Fiske-Jackson et al., 2013).Therefore, this technique has been recommended in combination with ultrasound (Fortier, 2005; Fiske-Jackson et al., 2013; Cauvin and Smith, 2014).

As ultrasound and contrast radiography do not always result in a final diagnosis, tenoscopy offers addi-

Table 1. Published sensitivities and specificities of ultrasound examination for lesions of the MF and the DDFT.

\begin{tabular}{lcccc}
\hline Reference & $\begin{array}{c}\text { MF } \\
\text { Sensitivity }\end{array}$ & Specificity & $\begin{array}{c}\text { DDFT } \\
\text { Sensitivity }\end{array}$ & Specificity \\
\hline Erdinger et al. (2005) & - & - & $90.5 \%$ & $53.8 \%$ \\
Arensburg et al. (2011) & - & $92 \%$ & $63 \%$ & $75 \%$ \\
Smith and Wright (2006) & $38 \%$ & $71 \%$ & $71 \%$ \\
\hline
\end{tabular}


tional diagnostic perspectives (Cauvin, 2003; Edinger et al., 2005; Jordana et al., 2013). The basis of endoscopic approach to the DFTS has been described by Nixon (1990), with slight modifications of the technique described by Wilderjans et al. (2003) and McIlwraith et al. (2015). Tenoscopic surgery is minimally invasive and can be used to diagnose lesions on the surface of the flexor tendons, the MF and the wall of the DFTS (Cauvin 2003; Davis and Smith, 2006).

In case of injury to the DDFT, SDFT and/or MF, loose fibers are debrided, adhesions and synovial masses within the DFTS can be removed (Fortier, 2005; Arensburg et al., 2011; Jordana et al., 2013). In case of a MF lesion, this structure, depending to the extent of pathology, can be removed partially or completely during the tenoscopic intervention (Smith and Wright, 2006; Schramme and Smith, 2010; Findley et al., 2012; Jordana et al., 2013). When preoperative ultrasonographic examination reveals thickening of the PAL, or in case of a functional constriction of the fetlock canal formed by the PAL, a desmotomy of the PAL can be performed during the tenoscopic intervention (Nixon et al., 1993; Fortier et al., 1999; Wilderjans et al., 2003; Smith and Wright, 2006; Owen et al., 2008; Jordana et al., 2013).

Postoperatively, the limb is bandaged for two to four weeks (Wright and McMahon, 1999; Wilderjans et al., 2003; Cauvin, 2003; Smith and Wright, 2006). Some authors recommend hand-walking starting three to four days postoperatively (Nixon, 2002). Usually, horses are treated postoperatively with NSAIDs for seven to ten days (Nixon, 2002; Smith and Wright, 2006; Jordana et al., 2013). The use of an intrasynovial injection of hyaluronic acid two weeks after the surgery has been described to reduce adhesion formation (Amiel et al., 1989; Moro-oka et al., 2000; Nixon, 2002), although in many cases, intrathecal administration of any medication is postponed until four to six weeks postoperatively.

The duration and intensity of convalescence depend on the primary injury and can vary from some weeks to several months (Wright and McMahon, 1999; Davis and Smith, 2006; Jordana et al., 2013).

The prognosis depends on the primary pathology causing the tenosynovitis (Schramme and Smith, 2010), and it has been described that the prognosis is better for lesions of the MF than for lesions of the DDFT (Davis and Smith, 2006; Smith and Wright, 2006; Arensburg et al., 2011; Findley et al., 2012; Jordana et al., 2013). Smith and Wright (2006) concluded that $67 \%$ of horses with lesions of the MF returned to their original level of performance, whereas $42 \%$ of cases with lesions of the DDFT returned to their pre-injury level of exercise, with a mean follow-up period of 21 months. The cosmetic result is generally guarded because of frequent chronic distension of the DFTS (Arensburg et al., 2011; Bertone, 2011).

The aim of this retrospective study was to describe the long-term results of tenoscopic treatment of noninfectious injuries in the DFTS.

\section{MATERIAL AND METHODS}

\section{Cases}

The medical records of all horses and ponies with non-infectious tenosynovitis of the DFTS treated tenoscopically at the Faculty of Veterinary Medicine of Ghent University from April 2008 to March 2016 were evaluated. Affected horses were classified according to their activity into jumping horses (including jumping, combined dressage and jumping, and eventing) and non-jumping horses (dressage, recreation, carriage driving, and horses only kept at pasture without athletic pursuits).

\section{Information and follow-up}

Relevant information derived from the patient records in the clinic database and telephone contact with the owner included date of consultation, age, sex, breed, primary level of training/competition, duration of lameness before the examination, previous problems with non-septic tenosynovitis or preceding treatment(s), affected $\operatorname{limb}(\mathrm{s})$, ultrasonographic, radiographic and tenoscopic findings, specific details regarding the tenoscopic intervention, postoperative treatment and rehabilitation, additional treatment(s), functional and cosmetic results, postoperative level of training/competition, and recurrent problems.

\section{Statistical analysis}

Chi-square analysis was performed to evaluate the association between the affected limb (front versus hind, left versus right) and the use of the horse (jumping versus non-jumping horses). Moreover, considering the results of the ultrasonographic versus tenoscopic evaluation, the sensitivity and specificity of ultrasonographic examination for lesions of the DDFT and the MF were calculated. Chi-square analysis was used to investigate: (1) the association between the number of injured structures and the return to the original level of performance, (2) the association between whether or not section of the annular ligament was performed and the cosmetic and functional result, and finally (3) the association between persistent swelling and lameness.

All statistical analyses were performed using GraphPad InStat3, with $\mathrm{P}<0.05$ considered statistically significant. Data are presented as mean \pm standard deviation (SD) unless stated otherwise.

\section{RESULTS}

\section{Clinical results}

Based on clinical records from the hospital database, fifty horses were included in this study. Ulti- 
Table 2. Prevalence of injuries in the right and left front and hind limbs in jumping and non-jumping horses.

\begin{tabular}{lccc}
\hline & Left & $\begin{array}{c}\text { Jumping horses } \\
\text { Right }\end{array}$ & Total \\
\hline Front limb & $\begin{array}{l}46.7 \%(7 / 15) \\
54.5 \%(6 / 11)\end{array}$ & $\begin{array}{l}53.3 \%(8 / 15) \\
45.5 \%(5 / 11)\end{array}$ & $\begin{array}{c}57.7 \%(15 / 26) \\
42.3 \%(11 / 26)\end{array}$ \\
\hline Hind limb & & Non-jumping horses & $20 \%(4 / 20)$ \\
\hline Front limb & $25 \%(1 / 4)$ & $75 \%(3 / 4)$ & $80 \%(16 / 20)$ \\
\hline Hind limb & $68.8 \%(11 / 16)$ & $31.3 \%(5 / 16)$ & \\
\hline
\end{tabular}

mately, follow-up information could be obtained from $40 / 50(80 \%)$ cases, with a mean \pm SD follow-up period of $4.6 \pm 2.5$ years.

Age ranged between 2 and 21 years (mean $\pm \mathrm{SD}$ $10.5 \pm 4.6$ years $)$. There were $60 \%$ mares $(30 / 50)$, $38 \%$ geldings $(19 / 50)$ and $2 \%$ stallions $(1 / 50)$. The horses' main discipline was only known for 42 horses, of which $57.1 \%(24 / 42)$ were classified as jumping horses [jumping $(17 / 42 ; 40.5 \%)$, dressage and jumping $(6 / 42 ; 14.3 \%)$, eventing $(1 / 42 ; 2.4 \%)]$ and $42.9 \%$ $(18 / 42)$ were classified as non-jumping horses [dressage $(5 / 42 ; 11.9 \%)$, recreation $(10 / 42 ; 23.8 \%)$, carriage driving $(1 / 42 ; 2.4 \%)$ or kept at pasture $(2 / 42$; $4.8 \%)$ ].

In three of the fifty horses, bilateral tenoscopy was performed (in one horse, both hind limbs presented a MF lesion; in one horse, both hind limbs had a DDFT lesion; in the third horse, the left hind limb had a MF lesion and the right hind limb had both a MF and a DDFT lesion). In the third horse, the left limb was even treated a second time six years later, revealing an additional DDFT lesion that was not detected during the initial surgery. Only in one of the three horses with bilateral lesions, tenoscopy was performed in both hind limbs at the same time. Therefore, in total, there were 54 tenoscopies in fifty cases. In general, no significant difference was observed between the number of affected hind limbs, in horses (28/46 or $60.9 \%)$ and in ponies $(6 / 8$ or $75 \%)$ compared with front limb injuries (18/46 or $39.1 \%$ in horses and $2 / 8$ or $25 \%$ in ponies $)(\mathrm{P}=0.445)$. However, a significantly higher prevalence $(\mathrm{P}=0.01)$ of the hind limb lesions was seen in non-jumping horses $(80 \% ; 16 / 20)$ compared with jumping horses $(42.3 \% ; 11 / 26)$. Thus, in jumping horses, the front limbs were affected more often $(57.7 \% ; 15 / 26)$.

In both jumping and non-jumping horses, there was no significant difference in prevalence of injuries to the left and right limb, as shown in Table 2.

\section{Ultrasonography}

In 51/54 (94.4\%) of cases, a complete ultrasonographic examination and corresponding report were available in the clinic database. In $23 / 51$ (45.1\%) of cases, tenoscopy revealed a DDFT lesion of which $15 / 23(65.2 \%)$ were accurately predicted by ultrasonography and 8/51(15.7\%) ultrasonographic examination were considered false negative (Figure 1). However, in 6/51(11.8\%) cases, the ultrasonography

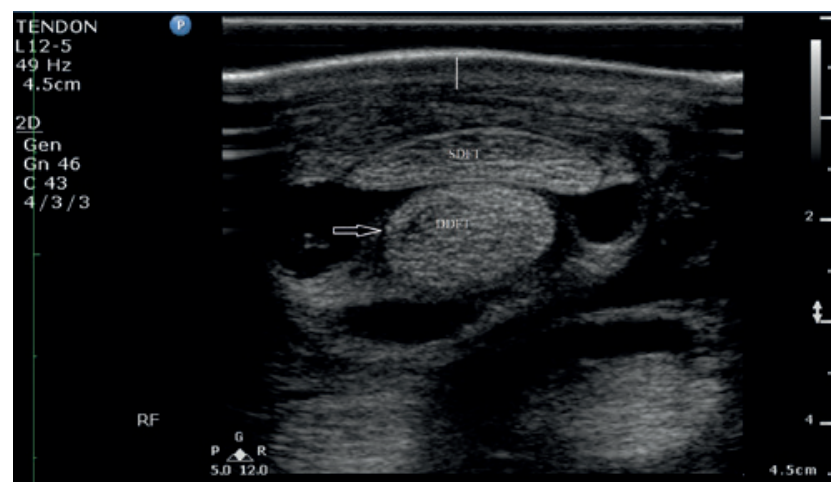

Figure 1. Transverse ultrasound image (lateral is to the left) of the proximal portion of the DFTS distended by anechoic fluid. There is a lesion at the lateral border of the DDFT, evident as a slightly irregular outline of the tendon surface (arrow) with a hypoechoic area within the lateral aspect of the DDFT. Also note the thickening of the subcutaneous tissues (vertical white line) and the wall of the digital flexor tendon sheath. DFTS= digital flexor tendon sheath; DDFT= deep digital flexor tendon; SDFT $=$ superficial flexor tendon.

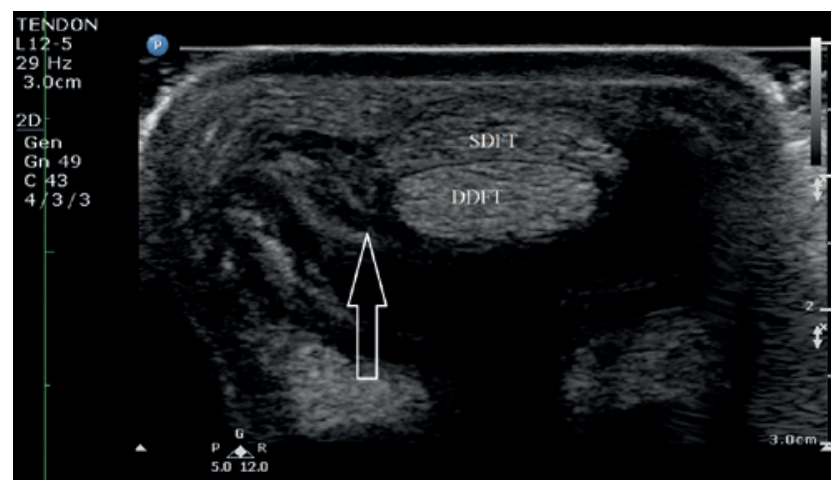

Figure 2. Transverse ultrasound image, proximal to the fetlock at the level of the MF. Complete rupture of the MF with a complete lateral dislocation (arrow). Note the distention of the DFTS with anechoic fluid. DDFT= deep digital flexor tendon; SDFT $=$ superficial digital flexor tendon; $\mathrm{MF}=$ manica flexoria. 

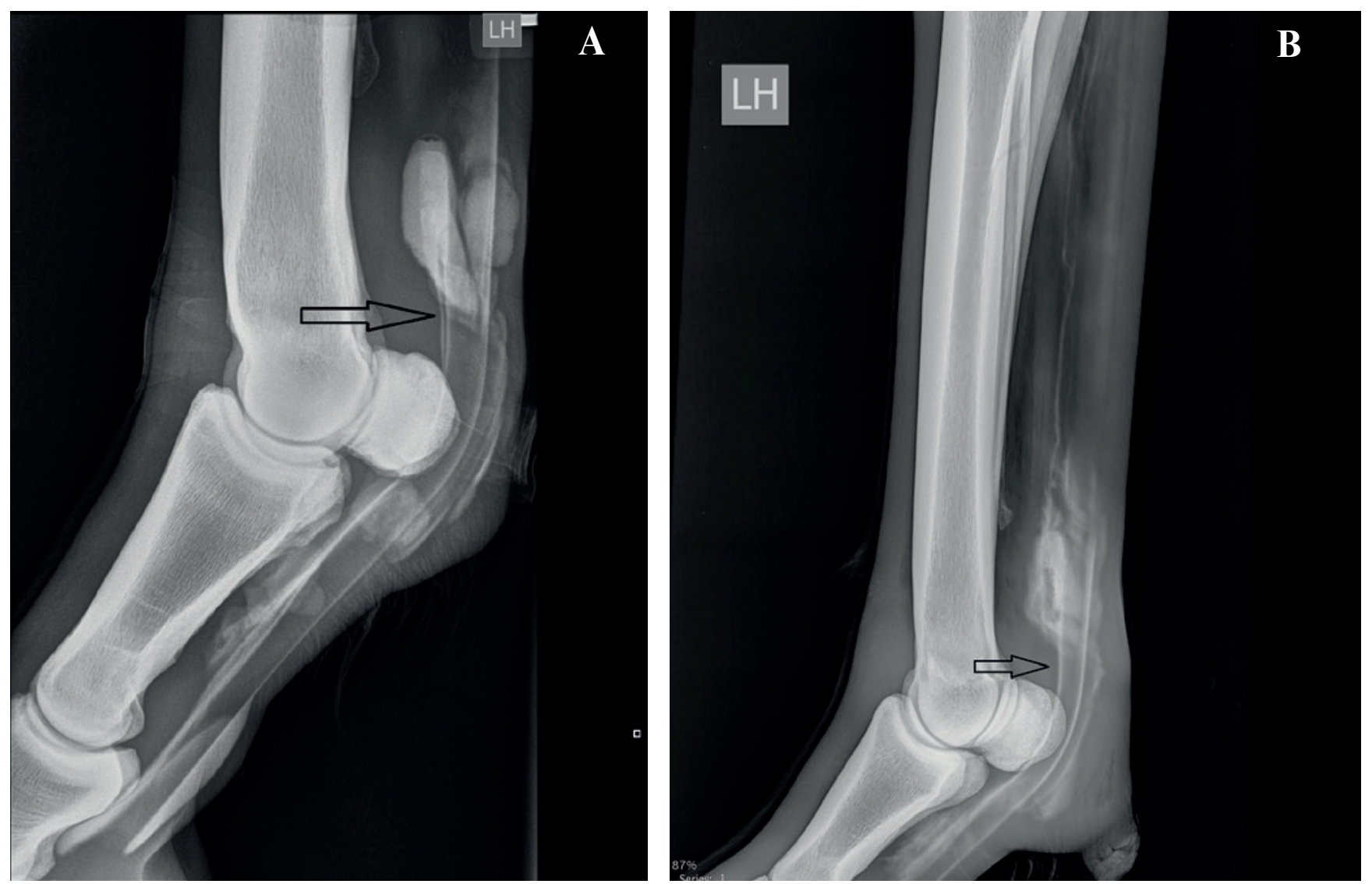

Figure 3. Contrast radiography of the DFTS. A. Normal DFTS with intact MF, visible as two parallel lines (arrow). The dorsal line is the MF and the palmar/plantar line is the dorsal limitation of the DDFT. B. Rupture of the MF. The MF is not visible, i.e. there is no double line visible (arrow), only the line at the dorsal aspect DDFT is visible. DFTS = digital flexor tendon sheath; MF = manica flexoria.

resulted in a false positive diagnosis of a DDFT lesion. Tenoscopy revealed MF lesions in 20/50 (40\%) cases, of which only $9 / 20(45 \%)$ were identified by ultrasound preoperatively (Figure 2). For MF lesions, there were only two false positive diagnoses after ultrasonographic examination.

The ultrasonographic data resulted in a sensitivity of $74.2 \%$ and a specificity of $82.4 \%$ for the diagnosis of lesions of the DDFT, whereas for lesions of the MF, the sensitivity of ultrasound was $64.5 \%$ and the specificity was $94 \%$.

Tears in the SDFT and primary lesions of the PAL were rarely diagnosed by tenoscopy $(8 / 54(14.8 \%)$ and $2 / 54(3.7 \%)$, respectively), while they were more often diagnosed by ultrasonographic examination (12/51 (23.5\%) and 9/51 (17.6\%), respectively).

Table 3. In 20/50 horses, radiographic information was available. In eleven of these twenty horses, more than one radiographic abnormality was noted.

\begin{tabular}{lcl}
\hline Radiographic findings & Number & In combination with \\
\hline Soft tissue swelling & 7 & $\begin{array}{l}\text { 1 Osteophytosis of the fetlock } \\
\text { Osteophytosis }\end{array}$ \\
Lesion MF & 4 & 1 Soft tissue swelling \\
No findings & 1 & - \\
Tarsus - no findings & 3 & - \\
Contrast radiography: & 1 & - \\
$\quad$ Lesion MF & 2 & - \\
$\quad$ Lesion DDFT & 2 & - \\
& 20 & \\
\hline
\end{tabular}




\section{Radiography}

In 20/50 horses, radiographic information was available. In eleven of these horses, more than one radiographic abnormality was noted (Table 3 ).

In $7 / 20(35 \%)$ cases, a soft tissue swelling could be seen at the palmar/plantar aspect of the fetlock or the pastern. In one (1/7) of these cases, degenerative changes (mild osteophytosis) at the level of the fetlock joint were also detected, and in 3/7 cases, soft tissue swelling in combination with mineralization of the soft tissues at the level of the second phalanx, the PAL or the lateral collateral ligament of the fetlock were observed. New bone formation (at the insertion of the PAL, the oblique sesamoidean ligaments, and the medial sesamoid bone) was also detected without other pathologies in 4/20 (20\%) cases. In 3/20 (15\%) cases, radiography did not reveal any abnormalities. In one case $(5 \%)$, a MF lesion was suspected, which was confirmed tenoscopically. Contrast radiography was performed in 4/20 cases: a tear of the MF was visualized in 2/20 cases, whereas a lesion of the DDFT was detected in the other $2 / 20$ cases (Figure 3 ). These findings were all confirmed tenoscopically.

\section{Tenoscopy}

All unilateral tenoscopies (52/54) were performed in lateral recumbency with the affected limb uppermost. Bilateral surgeries $(2 / 54)$ were performed in dorsal recumbency.

In $47 / 54(87 \%)$ cases, only one structure within the DFTS was injured, whereas in 3/54 (5.6\%) cases, multiple injuries were noticed (in particular DDFT lesions in combination with MF or SDFT lesions), and in 4/54 (7.4\%) cases, tenoscopy could not reveal any gross pathology. Altogether, lesions of the DDFT were most frequently diagnosed $(25 / 54 ; 46.3 \%)$ (Figure 4), while the MF was injured in 19/54 (35.2\%) cases (Figure 5), SDFT injury was seen in $8 / 54$ $(14.8 \%)$ cases and PAL pathology was detected in 2/54 (3.7\%) cases. DDFT and especially MF lesions were seen more frequently in the hind limbs than in the front limbs $(13 / 25 ; 52 \%$ and $16 / 19 ; 84 \%$, respectively). In all DDFT and SDFT tears, torn fibers were removed using a mechanical shaver (Dyonics Power, Smith and Nephew, Hamburg, Germany). Care was taken to debride torn fibers from the most proximal to the most distal aspect of the lesion.

The MF was partially removed in 9/19 (47.4\%) cases and completely removed in 8/19 (42.1\%) (Figure 6$)$. The remaining two cases $(10 \%)$ were only shaved, debrided and flushed.

In $23 / 54(42.6 \%)$ cases, the PAL was sectioned. The main indication was in $6 / 23(26.1 \%)$ cases a constriction or swelling of the annular ligament itself and in 16/23 (69.6\%) cases, the annular ligament was sectioned in combination with the treatment of other lesions within the DFTS, in order to release the tension within the fetlock canal. In 1/23 (4.3\%) case, no lesion was diagnosed during tenoscopy, but ultrasonographically and also radiographically, an insertion desmopathy was visualized; new bone formation was noted at the level of the medial insertion of the PAL.

\section{Postoperative care and rehabilitation}

Postoperatively, all patients were treated with NSAIDs for two to seven days (mean 3.6 \pm 1.1 days). Antibiotic therapy was only given in seven cases $(6 / 7$ penicillin, for two to three days and 1/7 doxycycline, for six days). These specific cases were more complex with severe tears of the DDFT and/or adhesions within the DFTS and/or section of the PAL or the MF. Routine postoperative care included regular bandage changes (every three to four days). Bandaging was continued until two or three days after removal of the skin sutures, which was performed 14 days after surgery.

In 33/54 (61.1\%) cases, injection of the DFTS with a corticosteroid, e.g. $12 \mathrm{mg}$ triamcinolone acetonide, with or without hyaluronic acid was advised, three to twelve weeks after surgery. Intrathecal injection of the DFTS was performed at the clinic in 16/33 (48\%) cases, whereas the other cases were treated by the referring veterinarian; there was no detailed information about the products and dosages used in those cases.

After tenoscopy, all horses started with a period of absolute box rest, varying from two days (small lesions of MF) to four weeks (severe lesions, desmotomy of the PAL and/or MF). The duration and intensity of rehabilitation varied according to the primary lesion. In most cases, the horses received controlled walking (preferably hand-walking) for four to six weeks, followed by gradual increasing ridden walking exercise, depending on the severity of the injury.

A follow-up visit at the clinic was recommended three months after surgery, or sooner if the owner noticed any problems. When the check-up revealed a favorable clinical course (decreased distension of the DFTS, decreased lameness), light trotting exercise was introduced until the next evaluation between four and six months after surgery. In cases with a positive evolution at the second check-up, the workload was gradually increased. Follow-up ultrasound examination was performed in 8/25 cases of DDFT tears, but was not performed in any of the MF tear cases $(0 / 19)$. Overall, 20/50 (40\%) returned to the clinic for followup visits. Of these, 13/20 cases returned once, 4/20 cases returned twice and 3/20 returned three times to the clinic for follow-up.

Some owners $(6 / 50 ; 12 \%)$ preferred an extended period of rest with the horse being used for breeding or kept at pasture; these horses did not follow the proposed schedule.

Additional therapeutic farriery was rarely performed; in most cases, the regular shoeing was con- 


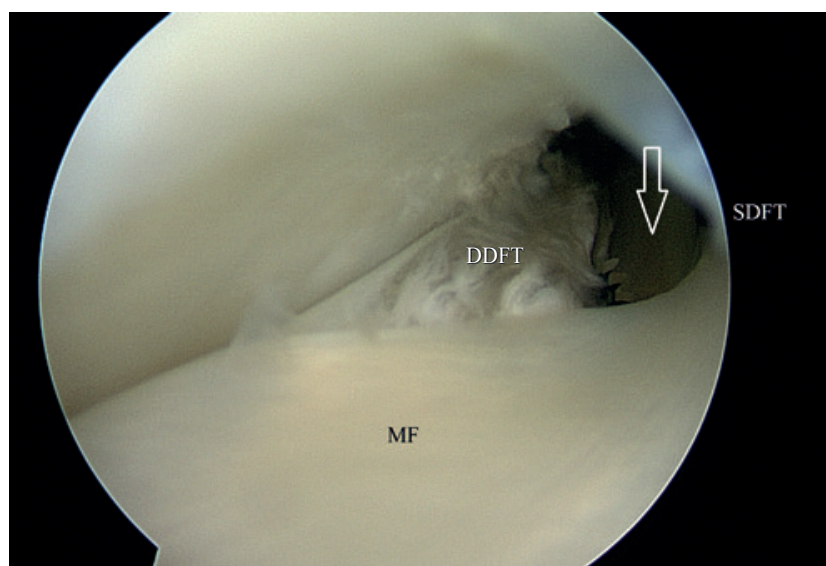

Figure 4. Tenoscopy of the DFTS with the scope positioned proximal of the annular ligament and directed distally. There is a tear at the lateral border of the DDFT. From a portal distal to the annular ligament, mechanical debridement of the lateral lesion of the DDFT is performed (arrow). This lesion extends under the MF. DFTS = digital flexor tendon sheath; DDFT = deep digital flexor tendon; $\mathrm{MF}=$ manica flexoria; SDFT = superficial digital flexor tendon.

tinued. Egg-bar shoes were used in one jumping horse with a DDFT lesion. No specific changes in the trimming or shoeing protocol were recommended in all other cases.

\section{Follow-up}

Follow-up information was available for $42 / 54$ tenoscopies (or 40/50 horses). Overall, 47.5\% (19/40) of the horses treated tenoscopically returned to their original level of performance, although the proportion of horses without lameness was 65\% (26/40). Thirty-five percent (14/40) of the horses remained lame and were not ridden anymore. There was no significant difference regarding the return to the original level of training or competition between cases with one $(19 / 39 ; 48.7 \%)$ or multiple lesions $(2 / 3 ; 66.7 \%)$ $(\mathrm{P}=0.592)$.

There were no significant associations between the functional and the cosmetic outcome after tears of the MF and DDFT: $66.7 \%(12 / 18)$ of the horses with tears in the DDFT became sound, which was not significantly different from $60 \%(9 / 15)$ of the horses with tears in the MF $(\mathrm{P}=0.692)$. For lesions of the DDFT, there was no postoperative effusion of the DFTS in only $27.8 \%(5 / 18)$ of the cases, while $46.7 \%(7 / 15)$ of the cases with lesions of the MF were without effusion $(\mathrm{P}=0.216)$.

In total, $27.7 \%(5 / 18)$ of the cases with lesions of the DDFT and $53 \%(8 / 15)$ of the cases with lesions of the MF returned to their original level of performance.

Tears in the SDFT and primary lesions of the PAL were rarely diagnosed (8/54 and $2 / 54$, respectively), precluding statistical analysis. However, $80 \%(4 / 5)$ of the horses with SDFT lesions were sound and $60 \%$ of them presented without any palpable abnormalities.

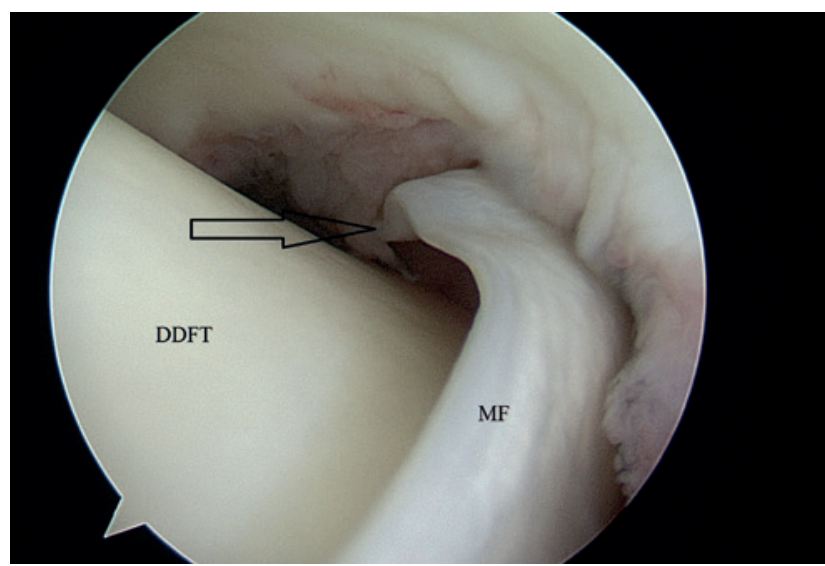

Figure 5. Tenoscopy of the DFTS. The scope is positioned just distal to the annular ligament and is directed proximally. Rupture of the MF (arrow). The distal border of the MF is not in close contact with the DDFT as a result of a tear of its medial attachment to the SDFT. DFTS= digital flexor tendon sheath; DDFT = deep digital flexor tendon; MF = manica flexoria; SDFT = superficial digital flexor tendon.

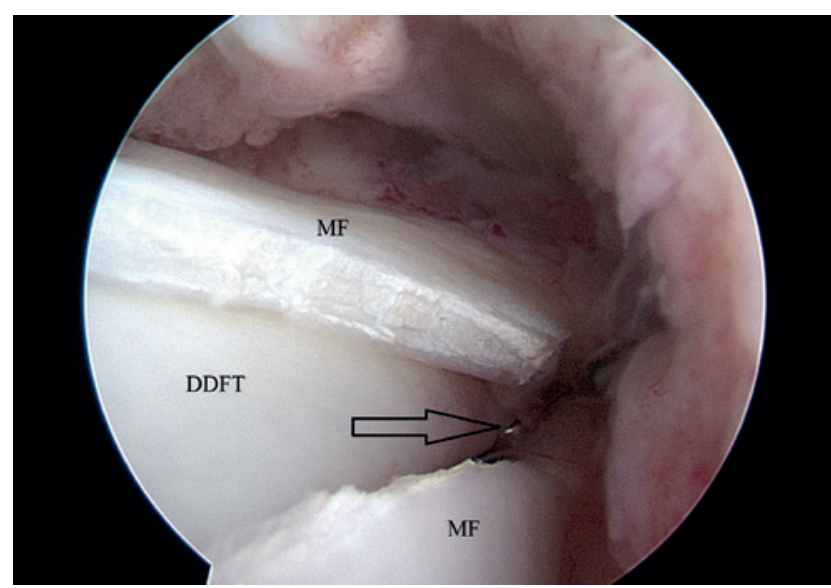

Figure 6. Tenoscopy of the DFTS. A hook knife (arrow) is used for the transection of the lateral attachment of the MF onto the SDFT allowing a complete resection of the MF. After transection the DDFT becomes clearly visible. DFTS = digital flexor tendon sheath; MF = manica flexoria; DDFT = deep digital flexor tendon; SDFT $=$ superficial flexor tendon.

One of the two cases with primary injury of the PAL was not lame and did not present any palpable abnormality.

In the study sample of fifty horses, 23 desmotomies of the PAL were completed in twenty of the horses. Follow-up information was only available for 15 of these horses. There was no significant association between desmotomy of the PAL and the final outcome (after desmotomy: 60\% (9/15) without lameness; without desmotomy: 68\% (17/35) without lameness). No postoperative effusion was noticed in $46.7 \%(7 / 15)$ of the horses with a desmotomy of the 
PAL, while in cases without desmotomy, there was no effusion in $52 \%(13 / 25)$.

There was a significant association between lameness and distension $(\mathrm{P}=0.02)$. Sixty-five percent (17/26) of the horses without lameness did not have any effusion postoperatively, whereas $78.6 \%(11 / 14)$ of the lame horses presented with distension of the DFTS after surgery.

As mentioned previously, there were more horses without lameness $(26 / 40)$ than horses performing at their original level (20/40). When these horses (6/26) were trained more intensively, they presented with lameness, and therefore, owners decided to use them for hacking (2/6), leisure (1/6), dressage at a lower level $(2 / 6)$ or for breeding purposes $(1 / 6)$.

\section{DISCUSSION}

This retrospective study documents the long-term results of tenoscopic treatment of fifty horses with non-infectious tenosynovitis. Through this study, it was possible to provide a mean follow-up period of 4.6 years, which is significantly longer than the period of 21 months reported in an earlier study by Smith and Wright (2006). Arensburg et al. (2011) reported a minimum follow-up of nine months but did not provide more details such as mean or median of the follow-up period.

In jumping horses, significantly more lesions were observed in the forelimbs than in the hind limbs, whereas in non-jumping horses, the hind limbs were affected more frequently. In a study by Smith and Wright (2006) and a study by Arensburg et al. (2011), lesions in the DDFT were seen more frequently in the fore limbs, and lesions in the MF were seen more frequently in the hind limbs. In contrast with Arensburg et al. (2011), who described a higher prevalence of DDFT lesions in the right forelimb in jumping horses, the current study revealed a higher frequency of lesions in the left fore limb. The reason for this difference remains unclear but may be linked to the smaller number of cases in this study and differences between the study samples.

Interestingly, the present study is the first to report a significant association between lameness and postoperative distension of the DFTS, highlighting the usefulness of a postoperative follow-up of these patients.

In agreement with the literature (Stashak, 2002; Fortier, 2005; Stanek, 2006), the present study sample confirms that tears in the DDFT $(25 / 54 ; 46.3 \%)$ and the MF $(19 / 54 ; 35.2 \%)$ are the most common injuries causing non-infectious tenosynovitis, and together, they make up more than $80 \%$ of the injuries encountered in this synovial structure.

In earlier studies, the prognosis of tears in the MF has been claimed to be better compared to DDFT lesions (Davis and Smith, 2006; Smith and Wright,
2006; Arensburg et al., 2011; Findley et al., 2012). In the study by Smith and Wright (2006), 67\% of horses with tears of the MF and $42 \%$ of horses with tears of the DDFT returned to their original level of performance. The long-term results of the current study could not reveal a statistically significant difference in either the cosmetic result for MF versus DDFT tears $(46.7 \% ; 7 / 15$ versus $27.8 \% ; 5 / 18)$, or the functional result for MF versus DDFT tears $(66.7 \%$; $12 / 18$ versus $60 \% ; 9 / 15)$.

Although ultrasonography is very useful for visualizing the underlying pathology, this study supports the previously described limitations of ultrasonography regarding sensitivity and specificity, especially for tears in the MF (Fortier, 2005; Smith and Wright, 2006; Fiske-Jackson et al., 2013). The current study reported false positive and false negative results for lesions in the DDFT and the MF. To overcome some of these limitations, contrast radiography has been recommended as a useful adjunctive technique (Fortier, 2005; Smith and Wright, 2006; Fiske-Jackson et al., 2013; Cauvin and Smith, 2014), and is currently part of the routine protocol at the Faculty of Veterinary Medicine (Ghent University) for patients with suspected pathology within the DFTS.

Regarding the long-term outcome after desmotomy of the PAL, the current study revealed rather disappointing cosmetic and functional results. After desmotomy of the PAL, $60 \%$ of the horses were not lame and $47 \%$ did not present any effusion, whereas without desmotomy of the PAL, $68 \%$ were not lame and $52 \%$ did not present any effusion. This may be subject to treatment bias, because very chronic or severe cases were more likely to be treated by desmotomy of the PAL. In a study by Owen et al. (2008), the success rate of desmotomy was also lower (42\%) than in other studies (McGhee et al., 2005), because of rather complicated cases with PAL desmopathy. Although previous studies have not identified an association between distension of the DFTS and clinical problems (Fortier et al., 1999; Stanek, 2006; Arensburg et al., 2011), this study has revealed a significant association between lameness and distension. Therefore, distension of the DFTS can be noted as a continuum of the pathology.

Interestingly, $65 \%$ of the horses were free of lameness after tenoscopy, but only $50 \%$ returned to their original level of training. The other horses (15\%) only tolerated a lower level of performance. Regarding the return to the original level of training, there was no significant difference between cases with single $(48.7 \%)$ or multiple lesions $(66.7 \%)$, although it is difficult to draw final conclusions on this comparison. Unfortunately, it is not known how many of these horses could perform at a lower level without surgery.

There is potential for improvement regarding the recommendations for therapeutic trimming and shoeing, especially in cases of DDFT pathology; egg-bar shoes or other forms of palmar/plantar support, in combination with optimized break-over, may be bene- 
ficial for these cases as recently reviewed by Oosterlinck et al. (2017).

The present retrospective clinical study suffers from the inherent limitations of a lack of control group, the lack of randomization of the treatment to individual cases and the heterogeneity of the study groups. Moreover, the long-term follow-up was obtained by telephone interview, relying on the owner's perception of each individual case.

\section{CONCLUSION}

The most frequent primary pathologies within the DFTS are tears of the DDFT and tears of the MF. After a follow-up period of $4.6 \pm 2.5$ years. $27.7 \%$ of the horses with DDFT injury and $53 \%$ of the horses with MF were able to return to their previous level of performance, which is a considerably poorer result than reported previously in studies with a shorter followup period. More research is needed to develop superior treatment strategies for horses with these lesions and provide evidence-based, long-term information on treatment efficacy.

\section{REFERENCES}

Amiel D., Kenneth I., Edmund B., Wiig M., van de Berg J., Akeson W.H., Gelberman R. (1989). Hyaluronan in flexor tendon repair. The Journal of Hand Surgery $14 \mathrm{~A}$, 837-843.

Arensburg L., Wilderjans H., Simon O., Dewulf J., Boussauw B. (2011). Nonseptic tenosynovitis of the digital flexor tendon sheath caused by longitudinal tears in the digital flexor tendons: A retrospective study of 135 tenoscopic procedures. Equine Veterinary Journal 43, 660668 .

Bertone A.L. (2011). The fetlock. In: Baxter G.M. (editor). Adams and Stashak's Lameness in Horses. Sixth edition, Wiley-Blackwell, West Sussex, pp. 594-620.

Cauvin E.R.J. (2003). Tenoscopy and bursoscopy. In: Dyson S.J., Ross M.W. (editors). Diagnosis and Management of Lameness in the Horse. First edition, Elsevier Science, St. Louis, Missouri, pp. 230-235.

Cauvin E.R.J., Smith R.K.W. (2014). Ultrasonography of the fetlock. In: Frazer K.L., Kidd J.A., Lu K.G. (editors). Atlas of Equine Ultrasonography. First edition, WilleyBlackwell, West Sussex, pp. 45-72.

Davis C.S., Smith R.K.W. (2006). Diagnosis and management of tendon and ligament disorders. In: Auer J.A., Stick J.A. (editors). Equine Surgery. Third edition, Saunders Elsevier, St. Louis, Missouri, pp. 1086-1111.

Dyce K.M., Sack W.O., Wensing C.J.G. (2010). Textbook of Veterinary Anatomy. Fourth edition, Saunders Elsevier, St. Louis, Missouri, pp. 604-609.

Edinger J., Möbius G., Fergusson J. (2005). Comparison of tenoscopic and ultrasonographic methods of examination of the digital flexor tendon sheath in horses. Veterinary and Comparative Orthopaedics and Traumatology 18, 209-214.

Findley J.A., De Oliveira F., Bladon B. (2012). Tenoscopic surgical treatment of tears of the manica flexoria in 53 Horses. Veterinary Surgery 41, 924-930.

Fiske-Jackson A.R., Barker W.H.J., Eliashar E., Foy K., Smith R.K.W. (2013). The use of intrathecal analgesia and contrast radiography as preoperative diagnostic methods for digital flexor tendon sheath pathology. Equine Veterinary Journal 45, 36-40.

Fortier L.A., Nixon A.J., Ducharme N.G., Mohammed H.O., Yeager A. (1999). Tenoscopic examination and proximal annular ligament desmotomy for treatment of equine "complex" digital sheath tenosynovitis. Veterinary Surgery 28, 429-435.

Fortier L.A. (2005). Indications and techniques for tenoscopic surgery of the digital flexor tendon sheath. Equine Veterinary Education 17, 218-224.

Hassel D.M., Stover S., Yarbrough B., Drake C.M., Taylor K.T. (2000). Palmar-plantar axial sesamoidean approach to the digital flexor tendon sheath in horses. Journal of the American Veterinary Medical Association 217, 1343 1347.

Jordana M., Oosterlinck M., Pille F., Valère A., Martens A. (2012). Comparison of four techniques for synoviocentesis of the equine digital flexor tendon sheath: A cadaveric study. Veterinary and Comparative Orthopedics and Traumatology 25, 178-183.

Jordana M., Martens A., Oosterlinck M. Vanderperren K., Pille F. (2013). Tenosynovitis van de sesamschede bij het paard: diagnostiek en behandeling. Vlaams Diergeneeskundig Tijdschrift 82, 225-233.

Jordana M., Martens A., Duchateau L., Vanderoerren K., Saunders J., Oosterlinck M., Pille F. (2011). Distal limb desensitisation following anaesthesia of the digital flexor tendon sheath in horses using four different techniques. Equine Veterinary Journal 46, 488-493.

König H.E., Liebich H.-G. (2008). Anatomie der Haussäugetiere: Lehrbuch und Farbatlas für Studium und Praxis. Vierte Auflage, Schattauer GmbH, Stuttgart, pp. 203-210.

McGhee J.D., White N.A., Goodrich L.R. (2005). Primary desmitis of the palmar and plantar annular ligaments in horses: 25 cases (1990-2003). Journal of the American Veterinary Medical Association 226, 83-86.

McIlwraith C.W., Nixon A.J., Wright I.M. (2015). Tenoscopy. In: McIlwraith C.W., Nixon A.J., Wright I.M. (editors). Diagnostic and Surgical Arthroscopy in the Horse. Fourth edition, Mosby, Elsevier, pp. 344-386.

Moro-oka T., Hiromasa M., Mawatari T., Kawano T., Nakanishi Y., Higaki H., Iwamoto Y. (2000). Mixture of hyaluronic acid and phospholipid prevents adhesion formation on the injured flexor tendon in rabbits. Journal of Orthopaedic Research 18, 835-840.

Nixon A.J. (1990). Endoscopy of the digital flexor tendon sheath in horses. Veterinary Surgery 19, 266-271.

Nixon A.J., Sams A.E., Ducharme N.G.(1993). Endoscopically assisted annular ligament release in horses. Veterinary Surgery 22, 501-507.

Nixon A.J. (2002). Arthroscopic surgery of the carpal and digital tendon sheaths. Clinical Techniques in Equine Practice 1, 245-256.

Oosterlinck M., Dumoulin M., Van de Water E., Pille F. (2017). Biomechanische aspecten met betrekking tot hoefbeslag bij paarden. Vlaams Diergeneeskundig Tijdschrift 86, 256-265.

Owen K.R., Dyson S.J., Parkin T.D.H., Singer E.R., Kristoffersen M., Mair T.S. (2008). Retrospective study of 
palmar/plantar annular ligament injury in 71 horses: 2001-2006. Equine Veterinary Journal 40, 237-244.

Schaller, O., Simoens P., Constantinescu G.M. (2007). Illustrated Veterinary Anatomical Nomenclature. Second edition, Enke Verlag, Stuttgart, p. 118.

Schneider R.K., Gavin P.R., Tucker R.L (2003). What magnetic resonance imaging is teaching us about navicular disease. In: Proceedings of the American Association of Equine Practitioners 49, 210-219.

Schramme M.C., Smith R.K. (2010). The soft tissues: Diseases of the digital flexor tendon sheath, palmar annular ligament, and digital annular ligament. In: Dyson S.J., Ross M.W. (editors). Diagnosis and Management of Lameness in the Horse. Second edition, Elsevier Saunders, St. Louis, pp. 764-776.

Smith M.R.W., Wright I.M. (2006). Noninfected tenosynovitis of the digital flexor tendon sheath: a retrospective analysis of 76 cases. Equine Veterinary Journal 38, 134141.
Stanek C. (2006). Erkrankungen der Fesselbeugensehnenscheide. In: Dietz O., Huskamp B. (editors). Handbuch der Pferdepraxis. Dritte Auflage, Enke Verlag, Stuttgart, pp. 933-941.

Stashak T.S. (2002). Adam's Lameness in Horses. Fifth edition, Lippincott Williams and Wilking, Philadelphia, pp. 630-640.

Wilderjans H., Boussauw B., Madder K., Simon O. (2003). Tenosynovitis of the digital flexor tendon sheath and annular ligament constriction syndrome caused by longitudinal tears of the deep digital flexor tendon: a clinical and surgical report of 17 cases in Warmblood horses. Equine Veterinary Journal 35, 370-375.

Wissdorf H., Gerhards H., Huskamp B. (1998). Praxisorientierte Anatomie des Pferdes. Erste Auflage, Verlag M. \& H. Schaper Alfeld, Hannover, pp. 315-316.

Wright I.M., McMahon P.J. (1999). Tenosynovitis associated with longitudinal tears of the digital flexor tendons in horses: A report of 20 cases. Equine Veterinary Journal 31, 12-18. 